\title{
The epidemiology of child and adolescent psychiatric disorders: recent developments and issues
}

\author{
ERIC FOMBONNE
}

Before 1960, few systematic surveys of behavioural and emotional problems in children were available in the literature. Most of psychopathological data therefore derived from the observation of clinical samples which are known to be sensitive to referral and other selection biases. As in many other fields of medical research, it was therefore imperative to generate knowledge about the rates, patterns and correlates of behavioural problems in non-referred children in order to derive a proper understanding of psychopathology. Epidemiology is the science which studies the repartition of disorders in human populations and the factors which influence this distribution. Epidemiological methods and designs were employed by psychiatric researchers in the 60s and 70 s and, progressively, a specific methodology for use in child psychiatric surveys was developed.

The Isle of Wight surveys conducted in Britain in the mid- and late-60s (Rutter et al., 1970; Rutter, 1989) represent a major development in child psychiatric epidemiology. The particular features of this survey were: a large sample size and a high participation rate; reliance on a two-stage survey design with a first screening stage based on questionnaires and a second interview stage of random samples of screened positive and negative children; the use of standardised diagnostic interviews of known reliability and validity; the use of impairment criteria to define psychiatric disorders; the combination of crosssectional design with longitudinal research strategies; and an examination of a wide range of biological and psychosocial risk factors (Rutter, 1989). Since then, numerous psychiatric surveys have been un-

Address for correspondence: Dr. E. Fombonne, Department of Child and Adolescent Psychiatry, Institute of Psychiatry, De Crespigny Park, London SE5 8AF (UK).

$\mathrm{Fax}+44$ (0)171-708.5800.

E-mail: e.fombonne@iop.bpmf.ac.uk dertaken throughout the world using similar methodology. The reader is referred to several recent reviews of these epidemiology inquiries for further details of the surveys (Bird, 1996; Brandenburg et al., 1990; Verhulst \& Koot, 1992; Roberts et al., 1998; Taylor et al., 1998). In particular, several surveys have been conducted in the last 15 years in European countries including Holland (Verhulst et al., 1985a, b), Norway (Vikan, 1985), the United Kingdom (Taylor et al., 1991), Ireland (Jeffers \& Fitzgerald, 1991), Germany (Esser et al., 1990), Finland (Puura et al., 1997), France (Fombonne, 1994a). Rather than to provide a detailed review of the methodology and substantial findings of these surveys, we outline some of the key outstanding issues in child and adolescent psychiatric epidemiological research.

\section{ISSUES OF DESIGN AND DATA ANALYSIS}

Most of the recent surveys have adopted a very complex survey strategy which relied on multistage stratified sampling, rather than on simple random sampling strategies. The efficiency of such complex surveys is improved but the drawback is that data must be analysed with complex weighting procedures and variance estimation is made more difficult. Examples of such studies which have relied on complex survey methods can be found in Bird et al. (1988); Fombonne, (1994a); Simonoff et al. (1997); and Costello et al. (1996). Surveys which have relied on school or classroom sampling methods have, in general, shown that, in the first screening stage of psychiatric surveys, children and their parents who refuse to participate show, on teacher questionnaires, higher rates indicative of higher levels of psychopathology. Designing an appropriate weight can compensate for the underestimation which results in the final prevalence estimate and such fine-tuned adjustments are now being made in recent surveys. 
Participation rates have otherwise been very high in child psychiatric surveys (see Brandenburg et al. 1990 ), often superior to $80 \%$ even in countries where empirical studies of children's behaviours and emotions have been traditionally under-developed (see Fombonne, 1994a). Investigators have also used different sampling fractions while drawing their samples from communities in order to have sufficient power and precision to estimate the prevalence of psychiatric disorders in specific subgroups such as children attending special schools or children from immigrant backgrounds.

\section{INSTRUMENTATION}

Whilst the earlier surveys relied on the Rutter Teacher and Parent questionnaires, the majority of studies conducted in the last 15 years have relied on the Child Behavior Checklist (CBCL) and its companion instruments (Achenbach, 1991a, b). The CBCL has good psychometric properties and provides a comprehensive rating system for common behavioural and emotional difficulties in a wide age range from 4 to 18 years old. As this questionnaire is normed for each population, it is particularly suitable for epidemiological and also clinical and longitudinal research. The CBCL and its related forms have been translated into most languages, and extensive cross-cultural research (Verhulst \& Achenbach, 1995) has shown the robust cross-cultural stability of the syndrome structure of this questionnaire. Investigators looking for briefer instruments, used for screening purposes only, may however be interested in the recent revisions of the Rutter scales by Goodman (1997) whose Strengths and Difficulties Questionnaire provides a short inventory suitable for both parents, teachers and youths themselves, and requires little time to complete.

Standardised diagnostic interviews have been refined since the Isle of Wight studies and now cover a more exhaustive range of specific psychiatric disorders which make them compatible with current diagnostic classifications such as DSM-IV (American Psychiatric Association, 1994) or ICD-10 (WHO, 1993). A review of the properties of existing diagnostic interviews has recently been provided by Hodges (1993). A traditional division between British and North American psychiatric research is reflected in the current development of standardised diagnostic interviews for children and adolescents. The British research tradition has relied on semi-structured inve- stigator-based instruments which require highly skilled interviewers with clinical experience, and whose own clinical judgment on the symptom pattern and associated impairment is crucial in reaching a final diagnostic formulation. By contrast, structured informant-based interviews rely on lay interviewers who ask questions to the informants and record their answers without further intervention of clinical judgment. The former approach is illustrated in the new Child and Adolescent Psychiatric Assessment (CAPA) (Angold et al., 1995), whereas the structured approach is embodied by the successive revisions of the Diagnostic Interview Schedule for Children (DISC) (Shaffer et al., 1993; Schwab-Stone et al., 1994).

Whilst it has been recognised that it is important to interview separately children or adolescents and their parents, it is still unclear what rules should be applied to the information arising from both interviews. It has typically been shown that the agreement between informants is low and most investigators rely on the so-called best estimate approach by which a symptom will be recognised as present if only one of the informants report it, potentially leading to an over-estimation of prevalence. Discrepancies in findings also arise from the assessment of impairments associated with psychiatric symptoms; thus, in the Puerto Rico investigation (Bird et al., 1988), the prevalence rate was $50 \%$ for any psychiatric disorder without the use of an impairment criterion, whilst the rate dropped to a much more realistic figure of $17 \%$ when an impairment criterion was added to the definition of psychiatric disorder. Computerised forms of interviews are currently being developed but it remains to be seen whether or not computerised interviews will achieve increased interview efficiency with no lessening of the validity.

\section{SUBSTANTIAL FINDINGS}

Across studies, the overall prevalence estimate of psychiatric disorders ranges from 12 to $20 \%$ (Roberts et al., 1998). Rates of disorders are high for oppositional defiant disorders and conduct disorders, and slightly lower (1 to $4 \%$ ) for attention deficit disorders (Taylor et al., 1998). Rates of depressive disorders are lower, not exceeding $1 \%$ in pre-puberal samples and in the 3 to $4 \%$ range for adolescent samples (Fombonne, 1998a). Rates of anxiety disorders are known with much less precision; there is also some uncertainty about the assessment and prevalence 
rates of psychiatric disorders in preschool children (Campbell, 1995). A consistent male preponderance has been found for disruptive disorders and females outnumber boys only for adolescent depression, eating disorders, suicide attempts and specific phobias. Comorbidity between disorders appears to be the rule rather than the exception.

The prevalence of autism has been estimated in 23 epidemiological studies (Fombonne, 1998c) and an average estimate for autism is $5 / 10.000$ children. Autism appears to have a 4 to 1 male/female ratio, to be equally common in all social classes, to be associated with mental retardation in $80 \%$ of cases, and to have a strong association with genetic medical disorders such as tuberous sclerosis and fragile $X$. The proportion of autism cases attributable to medical disorders does not, however, exceed 8 to $10 \%$ (Fombonne $e t$ al., 1997). In most autism surveys, a large group of children falling short of diagnostic criteria for autism, often labeled PDDNOS, has been identified. It is estimated that the prevalence of this group of conditions might be 1.5 times that of strictly defined autism (Fombonne 1998c). It will be important that future epidemiological studies focus on this needy group of children, as well as on other variants of autism such as Asperger syndrome for which only one survey is available (Ehlers \& Gillberg, 1993).

\section{SECULAR TRENDS}

One goal of epidemiology is to monitor rates of disorders over time in order to detect changes in the incidence and prevalence of disorders which might point towards causal explanations. There is now abundant evidence that rates of common psychosocial disorders in young people have increased since World War II (Rutter \& Smith, 1995; Fombonne, 1998d). The increase over time has been most pronounced for juvenile delinquency and conduct disorders which, in the four decades which followed the Second World War, were on average multiplied by a factor of 5 across countries (Rutter \& Smith, 1995). Rates of substance misuse including alcohol and other drugs have also increased enormously and continue to represent a serious public health problem in many Western countries. Suicide rates and rates of attempted suicide have also gone up with most of the increase taking place in the $1960 \mathrm{~s}$ and 1970s in many countries. Suicide has now become one of the two or three leading causes of death in young males aged 15 to 24 in several countries. The increase of suicide has been more pronounced in males, whereas trends in females have been more erratic. The data on the changing patterns of the incidence of depression are more indirect but the evidence suggests that lifetime rates of depression have increased in recent birth cohorts (Fombonne, 1994b; 1995a), a finding which cannot be accounted for by instrumentation, differential recall and mortality and other methodological artifacts. It also appears that there has been a lowering of the age of first onset for depressive episodes, with the onset being most common in adolescents nowadays. The evidence for an increase of eating disorders in females is more equivocal, with no strong evidence that rates of anorexia nervosa would have gone up (Fombonne, $1995 \mathrm{~b}, \mathrm{c})$, whereas trends in rates of bulimia nervosa are more difficult to gauge due to the recency of its description in the psychiatric literature and to a general lack of good epidemiological data thus far (Fombonne, 1996a; 1995c).

It is striking that, in a century where physical health and economical wealth have improved, this is not reflected in the mental health of young people. On the contrary, all the evidence suggests that rates of the most common psychosocial problems have increased. The causal explanations for this increase over time are not straightforward. It appears that, to some extent and reflecting the high degree of comorbidity between these disorders, the rise of some disorders could be attributed to the increase in other disorders. Thus, one recent study on increasing rates of suicidal behaviours suggested that the increase over time in suicidality in referred male adolescents was driven by a parallel increase in rates of substance misuse in this clinical sample, particularly of alcohol abuse (Fombonne, 1998b). Many pointers suggest that adolescent development is now extending over a long period of time, with increased years spent in education, different family life patterns with increased likelihood of parental separation, more influence of the peer and youth culture, concurring in an increased vulnerability of individual adolescent development (Rutter \& Smith, 1995). The usefulness of monitoring trends in various mental health indices in young people should remain a priority and research into the causes of this increased incidence of mental health problems should certainly be developed.

There is more debate about the possibility of a secular increase in rates of autism (Fombonne, 1996c; Fombonne, 1998c). Thus far, it appears that the trend towards higher prevalence rates of autism in 
most recent surveys does reflect changes in diagnostic definitions and improved case identification in surveys, rather than a true increase in the incidence of the disorder in the corresponding populations.

\section{LONGITUDINAL RESEARCH}

Cross-sectional surveys are useful to estimate the prevalence rates and therefore the needs for services in defined populations. They can also point towards variables which are associated with variations in the rates of prevalence. However, in order to move from statistical associations to causal links, reliance on longitudinal research is necessary (Fombonne, $1994 \mathrm{c})$. The second wave of surveys in the Isle of Wight allowed, for example, a follow-up four years later of children who had a psychiatric disorder at age 10. This follow-up was informative in showing that conduct disorder tended to persist at high rates whereas emotional disorders had remitted in half of the cases (Rutter et al., 1976). Subsequent epidemiological surveys have also benefited from longitudinal designs. Major lessons have been learnt, for example from the longitudinal birth cohort studies conducted in New Zealand, both in Christchurch (Fergusson $\boldsymbol{e t}$ al., 1994; Fergusson \& Lynskey, 1995) and Dunedin (Anderson et al., 1987; McGee et al., 1984; Caspi et al., 1996). The power of predictions over time is, for example, illustrated in one recent finding of the Dunedin study where behavioural styles observed at age 3 during a 30 minute laboratory session were predictive of adult psychopathology at age 21 (Caspi et al., 1996). Longitudinal studies are also necessary to identify factors which are associated with the offset of a disorder rather than with its persistence. Thus, the protective effect of positive school and peer experiences has been shown to promote healthier developmental trajectories in vulnerable adolescents and research about transitions and turning points over the life-span has developed out of the extensive analysis of longitudinal datasets (Rutter, 1996). Longitudinal studies have also been crucial in showing the links between childhood and adult disorders as exemplified by the strong and specific increased risk of adult depression following an index depressive episode in childhood (Harrington et al., 1990; 1996). Prospective investigators should, therefore, be strongly encouraged to build a longitudinal component to any epidemiological cross-sectional survey in preparation.

\section{CONCLUSION}

Epidemiological inquiries have been pivotal in the developing of child and adolescent psychopathology models in the last 30 years. A set of methods and instruments are available to conduct epidemiological surveys in most countries. Cross-sectional epidemiological surveys have often been the starting point of empirical research in child psychiatry in countries where scientific approaches have now been developed. Whilst it is useful to study patients referred to services and to infer from their treatment theories about the causation of disorders, observations arising from the clinics (and the theories which derive from them) cannot have an holistic value unless they are adequately tested in population studies. Pretty much as the study and treatment of diabetic or hypertensive patients could not be done without a knowledge of what is normal blood pressure or glucose regulation, child psychiatry practice must be calibrated against normal child development. A powerful tool to investigate normal patterns of behavioural and emotional development in children and adolescents is epidemiology which can foster our understanding of the links between disorders and normal development, of the risk factors which lead to the onset, persistence and offset of psychiatric disorders, of the natural history of specific psychiatric conditions, of factors which are associated with referral and contact with services, and of both the developmental antecedents and long term outcomes of child psychopathology.

\section{REFERENCES}

Achenbach T.M. (1991a). Integrative Guide for the 1991 CBCL/418, YSR and TRF Profiles. University of Vermont, Department of Psychiatry: Burlington, VT.

Achenbach T.M. (1991b). Manual for the Child Behavior Checklist 4-18 and 1991 Profile. University of Vermont, Department of Psychiatry: Burlington, VT.

American Psychiatric Association (1994). Diagnostic and Statistical Manual of Mental Disorders ( $4^{\text {th }}$ ed.). American Psychiatric Association: Washington DC.

Anderson J.C., Williams S., McGee R. \& Silva P. A. (1987). DSMIII disorders in preadolescent children. Prevalence in a large sample from the general population. Archives of General Psychiatry 44, 69-76.

Angold A., Prendergast M., Cox A., Harrington R., Simonoff E. \& Rutter M. (1995). The child and adolescent psychiatric assessment (CAPA). Psychological Medicine 25, 739-753.

Bird H.R. (1996). Epidemiology of childhood disorders in a crosscultural context. Journal of Child Psychology and Psychiatry $37(1), 35-49$. 
Bird H.R., Canino G., Rubio-Stipec M., Gould M.S., Ribera J., Sesman M., Woodbury M., Huertas S., Pagan A., Sanchez-Lacay A. \& Moscoso M. (1988). Estimates of the prevalence of childhood maladjustment in a community survey in Puerto Rico. Archives of General Psychiatry 45, 1120-1126.

Brandenburg N.A., Friedman R.M. \& Silver S.E. (1990). The epidemiology of childhood psychiatric disorders: prevalence findings from recent studies. Journal of the American Academy of Child and Adolescent Psychiatry 29, 76-83.

Campbell S.B. (1995). Behavior problems in preschool children: a review of recent research. Journal of Child Psychology and Psychiatry 36(1), 113-149.

Caspi A., Moffitt T.E., Newman D.L. \& Silva P.A. (1996). Behavioral observations at age 3 years predict adult psychiatric disorders: Longitudinal evidence from a birth cohort. Archives of General Psychiatry 53, 1033-1039.

Costello E., Angold A., Burns B., Kerkanli A., Stangl D. \& Tweed D. (1996). The Great Smoky Mountains Study of Youth: functional impairment and serious emotional disturbance. Archives of General Psychiatry 53, 1137-1143.

Ehlers S. \& C. Gillberg (1993). The epidemiology of Asperger syndrome. A total population study. Journal of Child Psychology and Psychiatry 34, 1327-1350.

Esser G., Schmidt M.H. \& Woerner W. (1990). Epidemiology and course of psychiatric disorders in school-age children. Results of a longitudinal study. Journal of Child Psychology and Psychiatry 31, 243-263.

Fergusson D.M. \& M.T. Lynskey (1995). Childhood circumstances, adolescent adjustment, and suicide attempts in a New Zealand birth cohort. Journal of the American Academy of Child and Adolescent Psychiatry 34(5), 612-622.

Fergusson D.M., Horwood L.J. \& Lynskey M.T. (1994). Parental separation, adolescent psychopathology and problem behaviors. Journal of the American Academy of Child and Adolescent Psychiatry 33(8): 1122-1133.

Fombonne E. (1994a). The Chartres study. I. Prevalence of psychiatric disorders among French school-aged children. British Journal of Psychiatry 164, 69-79.

Fombonne E. (1994b). Increased rates of depression: update of epidemiological findings and analytical problems. Acta Psychiatrica Scandinavica 90, 145-156.

Fombonne E. (1994c). Le role de l'epidemiologie dans la recherche etiologique en psychiatrie: Des facteurs aux mechanismes de risque. Revue d'Epidemiologie et de Sante Publique 41, 263-276.

Fombonne E. (1995a). Depressive disorders: time trends and possible explanatory mechanisms. In Psychosocial Disorders in Young People: Time Trends and their Causes (ed. M. Rutter and D.J. Smith), pp. 544-615. Wiley: Chichester.

Fombonne E. (1995b). Anorexia nervosa: no evidence of an increase. British Journal of Psychiatry 166, 462-471.

Fombonne E. (1995c). Eating disorders: time trends and possible explanatory mechanisms. In Psychosocial Disorders in Young People: Time Trends and their Causes (M. Rutter and D.J. Smith), pp. 616-685. Wiley: Chichester.

Fombonne E. (1996a). Is bulimia nervosa increasing in frequency? International Journal of Eating Disorders 19(3), 287-296.

Fombonne E. (1996b). Is the prevalence of autism increasing? Journal of Autism and Developmental Disorders 6, 673-676.

Fombonne E. (1998a). The management of depression in children and adolescents. In Handbook on the Management of Depression (ed. S. Checkley), pp. 345-363. Blackwell Publications: Oxford.

Fombonne E. (1998b). Suicidal behaviours in vulnerable adole- scents: time trends and their correlates. British Journal of Psychiatry 173, 154-159.

Fombonne E. (1998c). Epidemiological surveys of infantile autism. In Autism and Pervasive Developmental Disorders: Monographs in Child Psychiatry No. 2 (ed. F. Volkmar), pp. 32-62. Cambridge University Press: Cambridge.

Fombonne E. (1998d). Increased rates of psychosocial disorders in youth. European Archives of Psychiatry and Clinical Neuroscience 248, 14-21.

Fombonne E., du Mazaubrun C., Cans H. \& Grandjean H. (1997). Autism and associated medical disorders in a large French epidemiology sample. Journal of the American of Child and Adolescent Psychiatry 36, 1561-1569.

Goodman R. (1997). The strengths and difficulties questionnaire: a research note. Journal of Child Psychology and Psychiatry 38(5), 581-586.

Harrington R., Fudge H., Rutter M., Pickles A. \& Hill J. (1990). Adult outcomes of childhood and adolescent depression - I. Psychiatric status. Archives of General Psychiatry 47, 465-473.

Harrington R., Rutter M. \& Fombonne E. (1996). Developmental pathways in depression: Multiple meanings, antecedents, and endpoints. Development and Psychopathology 8, 601-616.

Hodges K. (1993). Structured interviews for assessing children. Journal of Child Psychology and Psychiatry 34(1). 49-68.

Jeffers A. \& M. Fitzgerald (1991). Irish Families Under Stress. Vol.2. Eastern Health Board: Dublin.

McGee R., Silva P. A. \& Williams S. (1984). Behaviour problems in a population of seven-year-old children: prevalence, stability and types of disorder. A research report. Journal of Child Psychology and Psychiatry 25(2), 251-259.

Puura K., Tamminen T., Almqvist F., Kresanov K., Kumpulainen K., Moilanen I. \& Koivisto A.-M. (1997). Should depression in young children be diagnosed with different criteria? European Child and Adolescent Psychiatry 6(1), 12-19.

Roberts R.E., Attkisson C.C. \& Rosenblatt A. (1998). Prevalence of psychopathology among children and adolescents. American Journal of Psychiatry 155(6), 715-725.

Rutter M. (1989). Isle of Wight revisited: twenty-five years of child psychiatric epidemiology. Journal of the American Academy of Child and Adolescent Psychiatry 28, 633-653.

Rutter M. (1996). Transitions and turning points in developmental psychopathology: as applied to the age span between childhood and mid-adulthood. International Journal of Behavioral Development 19(3), 603-626.

Rutter M. \& D.J. Smith (ed.) (1995). Psychosocial Disorders in Young People: Time Trends and their Causes. Wiley: Chichester.

Rutter M., Tizard, J. \& Whitmore K. (1970). Education, Health and Behaviour. Longmans: London.

Rutter M., Tizard J., Yule W., Graham P. \& Whitmore K. (1976). Research report: Isle of Wight studies, 1964-1974. Psychological Medicine 6, 313-332.

Schwab-Stone M., Fallon T., Briggs M. \& Crowther B. (1994). Reliability of diagnosting reporting for children aged 6-11 years: a test-retest study of the Diagnostic Interview Schedule for Children-Revised. American Journal of Psychiatry 151, 10481054.

Shaffer D., Schwab-Stone M., Fisher P., Cohen P., Piacentini J., Davies M., Conners K. \& Regier D. (1993). The Diagnostic Interview Schedule for Children-Revised version (DISC-R): 1 Preparation, field testing, interrater reliability and acceptability. Journal of the American Academy of Child and Adolescent Psychiatry 32, 643-650. 
Simonoff E., Pickles A., Meyer J.J., Silberg J.L., Maes H.H., Loeber R., Rutter M., Hewitt J.K. \& Eaves L.J. (1997). The Virginia Twin Study of Adolescent Behavioral Development: influences of age, gender and impairment in rates of disorder. Archives of General Psychiatry 54, 801-808.

Taylor E., Fombonne E. \& Danckaerts M. (1998). Epidemiology of Mental Disorders in Childhood. World Health Organisation: Geneva.

Taylor E., Sandberg S., Thorley G. \& Giles S. (1991). The Epidemiology of Childhood Hyperactivity. Oxford University Press: Oxford.

Verhulst F.C. \& Achenbach T.M. (1995). Empirically based assessment and taxonomy of psychopathology: Cross-cultural applications. A review. European Child and Adolescent Psychiatry 4(2), 61-76.
Verhulst F, C. \& Koot H.M. (1992). Child Psychiatric Epidemiology: Concepts, Methods and Findings. Sage: Newbury Park, CA.

Verhuist F.C., Akkerhuis G.W. \& Althaus M. (1985a). Mental Health in Dutch Children: I. A Cross-cultural Comparison. Acta Psychiatrica Scandinavica, Supplementum No. 323, vol. 72, pp. 1-108.

Verhulst F.C., Berden G.F., Sanders-Woudstra J.A. (1985b). Mental Health in Dutch Children: II. The Prevalence of Psychiatric Disorder and Relationship between Measures. Acta Psychiatrica Scandinavica, Supplementum 324, vol. 72 pp. 1-45.

Vikan A. (1985). Psychiatric epidemiology in a sample of 1510 tenyear-old children - I. Prevalence. Journal of Child Psychology and Psychiatry 26(1), 55-75.

World Health Organization (1993). The ICD-10. Classification of Mental and Behavioural Disorders. Diagnostic Criteria for Research. World Health Organisation: Geneva. 